\title{
Tenascin-C promotes epithelial-to-mesenchymal transition and the mTOR signaling pathway in nasopharyngeal carcinoma
}

\author{
XIANG CHENG, FEN LI and ZEZHANG TAO \\ Department of Otolaryngology-Head and Neck Surgery, \\ Renmin Hospital of Wuhan University, Wuhan, Hubei 430060, P.R. China
}

Received December 5, 2020; Accepted April 22, 2021

DOI: $10.3892 / \mathrm{ol} .2021 .12831$

\begin{abstract}
Tenascin-C (TNC) is a large extracellular matrix glycoprotein that promotes cell adhesion and tissue remodeling, and is involved in the transduction of cellular signaling pathways. The present study aimed to investigate the role of TNC and determine its effect in nasopharyngeal carcinoma (NPC). TNC gene transcription and expression were analyzed using the NPC dataset and immunohistochemistry analysis of NPC tissues. Weighted gene co-expression network and gene enrichment analyses were performed to determine the potential molecular mechanisms underlying the effects of TNC in NPC. TNC expression was suppressed in NPC cells, and the effects were determined both in vitro and in vivo. The results demonstrated that TNC gene transcription and expression were high in NPC tissues compared with normal tissues. Notably, TNC knockdown inhibited NPC cell proliferation, migration and invasion. In addition, TNC knockdown inhibited tumor growth in mice. In vitro, TNC knockdown inhibited epithelial-to-mesenchymal transition (EMT) and decreased activity of the PI3K/AKT/mTOR signaling pathway in NPC cells. Taken together, these results suggest that TNC promotes cell proliferation, EMT and activity of the PI3K/AKT/mTOR signaling pathway in NPC cells, and thus functions as an oncogene.
\end{abstract}

\section{Introduction}

Nasopharyngeal carcinoma (NPC) is a malignant tumor of the nasopharynx, which is commonly observed in Southeast Asia and Southern China $(1,2)$. NPC is radiosensitive; thus radiotherapy is one of the primary methods of treatment (3). NPC arises from the epithelium of the nasopharyngeal

Correspondence to: Professor Zezhang Tao, Department of Otolaryngology-Head and Neck Surgery, Renmin Hospital of Wuhan University, 238 Jie-Fang Road, Wuhan, Hubei 430060, P.R. China E-mail: taozezhang@126.com

Key words: tenascin-c, weighted gene co-expression network analysis, epithelial-to-mesenchymal transition, nasopharyngeal carcinoma, gene set enrichment analysis mucosa $(4,5)$. Patients with early-stage NPC that are treated with intensity-modulated radiotherapy have a 5-year overall survival rate $>90 \%$ (6). However, patients with locally advanced NPC have a poor prognosis, with a 5-year overall survival rate of $40-70 \%$, due to a high incidence of metastases to distant organs and the development of a radioresistant tumor $(7,8)$. Thus, it is important to understand the mechanism by which NPC rapidly progresses to improve the survival of patients with NPC.

Tenascin-C (TNC) is a large extracellular matrix (ECM) glycoprotein composed of a six-armed quaternary and multi-module structure (9). TNC contributes to several functions, such as cell adhesion, tissue remodeling, and tumor cell migration and invasion owing to the presence of alternatively spliced isoforms and the various domains present (10). In adults, its expression is physiologically low, and abnormally high TNC expression is associated with several diseases, including atherosclerosis, thrombosis, heart failure and cancer $(11,12)$. TNC has been widely reported in the tumor stroma of most epithelial malignancies with increased deposition, including ovary, stomach, colon, mouth and larynx cancer $(10,13)$. In addition, TNC plays a key role in tumor progression in several types of cancer, including breast cancer, glioma, colorectal cancer and glioblastoma (14-17). Several studies have demonstrated that TNC promotes epithelial-to-mesenchymal transition (EMT), facilitates cell adhesion and accelerates cell invasion in tumors $(16,18-20)$. To the best of our knowledge, the role of TNC in NPC has not yet been determined; however, it is hypothesized that TNC may be involved in NPC progression, which was investigated in the present study.

The weighted gene co-expression network analysis (WGCNA) method was established by Langfelder and Horvath in 2008 (21), and it has proved to be a useful method to characterize the patterns of gene association in microarray data and to determine modules or co-expression networks based on related genes (22). Thus, WGCNA was performed in the present study to identify significant module highly synergistic with TNC expression in NPC.

The present study aimed to investigate TNC expression in NPC samples and its association with malignant progression of NPC via immunohistochemistry (IHC) analysis. Gene expression in Gene Expression Omnibus (GEO) datasets was analyzed via WGCNA to identify TNC co-expressed genes in NPC. TNC knockdown NPC cells were constructed and 
the effect of TNC on the biological functions of NPC cells was investigated both in vitro and in vivo. Furthermore, the potential molecular mechanism of TNC in NPC was predicted via gene enrichment analysis and verified via western blotting.

\section{Materials and methods}

TNC expression in NPC tissues. The raw data of TNC expression in NPC tissues and normal nasopharyngeal tissues were downloaded from the GEO database (ncbi.nlm.nih.gov/geo), including two datasets, GSE53819 (23) and GSE13597 (24). In addition, the GSE103611 dataset (25) was downloaded from the GEO database, which included data of gene expression between 24 NPC non-metastatic tissues and 24 NPC metastatic tissues. An NPC tissue microarray (TMA) was purchased from Guilin Fanpu Biotech (http://www.fanpu.com/aboutus/aboutus.htm). There were 150 patients in the TMA, including 115 NPC cases and 35 nasopharyngitis (NPG) cases. The inclusion and exclusion criteria were as follows: i) None of the patients had received antitumor therapy prior to biopsy; ii) the pathological data of patients with NPC were complete. Among the patients with NPC, there were 78 men and 37 women. The median age of patients with NPC was 48.3 years (age range, 24-78 years), and the average age was $49.47 \pm 7.32$ years. The present study was approved by the Clinical Research Ethics Committee of Renmin Hospital of Wuhan University [Wuhan, China; approval no. 2020(421)] and written informed consent was provided by all patients prior to the study start.

IHC. TNC expression was detected in patients in the TMA via IHC analysis. The TMA was dewaxed and hydrated after heating in a thermostat at $60^{\circ} \mathrm{C}$ for $20 \mathrm{~min}$. For antigen retrieval, the TMA was placed in sodium citrate buffer (10 M, pH 6.0) and heated at $95^{\circ} \mathrm{C}$ for $10-15 \mathrm{~min}$. Normal goat serum blocking solution (cat. no. C0265; Beyotime Institute of Biotechnology) was added dropwise to the TMA at room temperature for 20 min to block the endogenous enzymes and antibodies in the tissue. The TMA was incubated with anti-TNC at $37^{\circ} \mathrm{C}$ for 30 min (1:100; cat. no. YT6187; ImmunoWay Biotechnology Company) to detect TNC expression. A non-immune IgG antibody (1:500; cat. no. C0265; Beyotime Institute of Biotechnology) was used as the negative control. Tissues stained with the fluorescently labeled antibodies were observed under a fluorescent microscope (magnifications, x100 and $\mathrm{x} 400$ ).

The percentage of TNC positive cells was calculated and scored as follows: $1,0-9 ; 2,10-50$ and $3,>50 \%$. The immunoreactive scores of TNC were scored as follows: 0 , negative; 1 , weak; 2 , moderate and 3 , strong. The scores were multiplied and graded as follows:,$- 0 ;+, 1-3 ;++, 4-6$ and +++, 7-9. Tissues graded as '-' and ' + ' were considered as the low expression TNC group, while ' ++ ' and '+++' were considered as the high TNC expression group (26).

Construction of WGCNA. The WGCNA R package 1.69 (Bioconductor) was used to construct the WGCNA on the GSE53819 dataset, which consisted of 18 patients with NPC and 18 healthy individuals (21). Genes with an expression $>0.1$ were screened in GSE53819 and used for the construction. Samples were clustered using hierarchical clustering by the average method to detect outliers before an appropriate soft threshold power was selected to finish standard scale-free networks. Subsequently, gene dendrogram and module identification were performed through the construction of adjacency and topological overlap matrix (TOM). Highly similar modules were merged by implementing the clustering of modular eigengenes, and the association between each module eigengene and TNC was calculated. The internal connectivity and module membership of each gene in the module that was most highly associated with TNC was used to screen for hub genes meeting the following criteria: Gene and specified module significance $>0.2$, modular membership value $>0.8$ and $\mathrm{q}<0.01$.

Biological function and pathway enrichment analyses. Gene Ontology (GO) and Kyoto Encyclopedia of Genes and Genomes (KEGG) pathway enrichment analyses (https://www.genome. $\mathrm{jp} / \mathrm{kegg}$ ) of hub genes were performed using the Molecular Signatures Database (gsea-msigdb.org/gsea/msigdb/annotate. jsp) (27). In addition, gene set enrichment analysis (GSEA) for the differentially expressed genes between the high and low TNC expression groups was performed using the same database.

Cell culture and lentiviral short hairpin RNA (shRNA) transfection. The human NPC cell lines, 5-8F and 6-10B, were purchased from the Laboratory of Molecular Tumor Pathology, Southern Medical University (Guanagzhou). Cells were maintained in DMEM (Thermo Fisher Scientific, Inc.) supplemented with $10 \%$ fetal bovine serum (FBS, Gibco; Thermo Fisher Scientific, Inc.), at $37^{\circ} \mathrm{C}$ with $5 \% \mathrm{CO}_{2}$.

Lentivirus transduction particles (Shanghai GeneChem Co., Ltd.) containing small interfering RNA (siRNA) targeting TNC and negative control siRNA were transduced into $5-8 \mathrm{~F}$ and $6-10 \mathrm{~B}$ cells. A total of $5 \times 10^{4}$ cells $/ \mathrm{ml}$ cell suspension with complete medium (90\% RPMI1640 media + 10\% Gibco Fetal Bovine Serum) was prepared and $2 \mathrm{ml}$ cell suspension/well was inoculated into 6-well plates. Cells were incubated at $37^{\circ} \mathrm{C}$ for 16-24 h until they reached $20-30 \%$ confluence. During transduction, $1 \mathrm{ml}$ of medium was discarded, and $40 \mu \mathrm{l}$ of HiTransG infection solution (Shanghai GeneChem Co., Ltd.) and $40 \mu \mathrm{l}$ of lentivirus solution (The MOI was 20 according to the pre-infection experiment and the virus titer was $1 \times 10^{8} \mathrm{TU} / \mathrm{ml}$ ) were added, and cells were cultured at $37^{\circ} \mathrm{C}$. After $16 \mathrm{~h}$, the medium was replaced with fresh medium. Transduction efficiency was observed via light and fluorescence microscopy (magnification, x100 times) after $72 \mathrm{~h}$. The successfully transduced cells had red fluorescence as there were GFP labels in the lentivirus particles. The stable cells were screened using puromycin $(2 \mu \mathrm{g} / \mathrm{ml})$ (Zhejiang Genom Co., Ltd.) for 14 days.

Cell proliferation assay. Cell proliferation was assessed via the Cell Counting Kit-8 (CCK-8) assay (Dojindo Molecular Technologies, Inc.) and the EdU cell proliferation assay (cat. no. C10310-1; Guangzhou RiboBio Co., Ltd.).

For the CCK-8 assay, 5-8F and 6-10B cells were seeded into 96 -well plates at a density of $4 \times 10^{3}$ cells/well. Cell proliferation was assessed after $0,24,48$ and $72 \mathrm{~h}$. A total of $100 \mu \mathrm{l}$ reagent, containing $10 \mu \mathrm{l}$ CCK-8 solution and $90 \mu \mathrm{l}$ serum-free 
media, was added to each well and the plates were incubated for $1 \mathrm{~h}$. The absorbance values were measured at a wavelength of $450 \mathrm{~nm}$, using a microplate reader (PerkinElmer, Inc.), and the proliferation curve was plotted.

For the EdU cell proliferation assay, 5-8F and 6-10B cells were seeded into 6-well plates at a density of $1 \times 10^{5}$ cells/well and cultured until they reached $80-90 \%$ confluence. Cells were subsequently labeled using Cell-Light ${ }^{\mathrm{TM}}$ EdU Apollo ${ }^{\circledR}$ 567 (Guangzhou RiboBio Co., Ltd.), according to the manufacturer's protocol, and observed under an automatic fluorescence microscope (magnification, x100).

Wound healing assay. For the wound healing assay, 5-8F and 6-10 B cells were seeded into 6-well plates. When the cells confluence reached $80-90 \%$, the cell monolayers were scratched using a $100 \mathrm{ul}$ sterile pipette tip, washed twice with PBS and incubated with FBS-free medium for $24 \mathrm{~h}$ at $37^{\circ} \mathrm{C}$. Cells were observed in five randomly selected fields using an optical microscope (magnification, x100). The distance between the two cell edges was measured and compared with the original distance of the gap using ImageJ 1.8.0 software (National Institutes of Health), and this was considered the wound healing rate.

Migration and invasion assays. 50,000 5-8F or 6-10 B cells in $200 \mu \mathrm{l}$ FBS-free media were plated in the upper chambers of Transwell plates (Corning, Inc.), which were pre-coated with Matrigel for the invasion assay for $2 \mathrm{~h}$ at $37^{\circ} \mathrm{C}(10 \mathrm{mg} / \mathrm{ml})$, but not the migration assay. A total of $600 \mu \mathrm{l}$ supplemented media was added to the lower chambers. Following incubation for $24 \mathrm{~h}$ at $37^{\circ} \mathrm{C}$, the migratory and invasive cells were stained with $0.1 \%$ purple crystal for $60 \mathrm{~min}$ at room temperature and counted in five randomly selected fields using a light microscope (magnification, x200 times).

Reverse transcription-quantitative $(R T-q) P C R$. Total RNA was extracted using TRIzol ${ }^{\circledR}$ reagent (Invitrogen; Thermo Fisher Scientific, Inc.) from 5-8F or 6-10 B cells and reverse transcribed (RT) into cDNA using the Super RT Reverse Transcriptase reagent kit (CoWin Biosciences). In RT process, reaction system including RNA was incubated at $42^{\circ} \mathrm{C}$ for $60 \mathrm{~min}$ to synthesize cDNA, then incubated at $80^{\circ} \mathrm{C}$ for $10 \mathrm{~min}$ to inactivate the reverse transcriptase and terminate the RT reaction. qPCR was subsequently performed using $\mathrm{SYBR}^{\circledR}$ Green MasterMix (Thermo Fisher Scientific, Inc.) on a 7500 Fast Real-Time PCR system (Applied Biosystems; Thermo Fisher Scientific, Inc.), according to the manufacturer's instructions. The thermocycling conditions for $\mathrm{qPCR}$ were as follows: Thermal denaturation for $3-5 \mathrm{~min}$ at $95^{\circ} \mathrm{C}$; amplification program for $30 \mathrm{sec}$ at $95^{\circ} \mathrm{C}, 60^{\circ} \mathrm{C}$ for $30 \mathrm{sec}$, cycle number was 40 ; final extension at $72^{\circ} \mathrm{C}$ for $5-10 \mathrm{~min}$; after all PCR reactions are completed, the temperature was maintained at $4-12^{\circ} \mathrm{C}$. The following primer sequences were used for qPCR: TNC forward, 5'-ACTGACTCAGAAGCC TTGG-3' and reverse, 3'-ATTTCTGGCACTTTCTCGC-5'; cadherin 1 (CDH1) forward, 5'-AGCACCTTCCATGACAGA CCC-3' and reverse, 5'-AGAACGCATTGCCACATACAC-3'; CDH2 forward, 5'-CATCATCATCCTGCTTATCCTTGT-3' and reverse, 5'-GGTCTTCTTCTCCTCCACCTTCTT-3'; vimentin (VIM) forward, 5'-ATCGTGATGCTGAGAAGT
TTCG-3' and reverse, 5'-TCTGGATTCACTCCCTCTGGT T-3'; snail family transcriptional repressor 2 forward, 5'-TTT TGCACTGGTATTTCTTTACATC-3' and reverse, 5'-CCC TGGTTGCTTCAAGGACAC-3'; and GAPDH forward, 5'-TGACTTCAACAGCGACACCCA-3' and reverse, 5'-CAC CCTGTTGCTGTAGCCAAA-3'. Relative expression levels were calculated using the $2^{-\Delta \Delta \mathrm{Cq}}$ method (28) and normalized to the internal reference gene GAPDH.

Western blotting. 5-8F and 6-10 B cells were collected and lysed using RIPA lysis buffer (Thermo Fisher Scientific, Inc.) containing protease and phosphatase inhibitors (Roche Applied Science). The supernatants were collected via centrifugation at $14,000 \mathrm{xg}$ for $20 \mathrm{~min}$ at $4^{\circ} \mathrm{C}$. Total protein was quantified using the BCA protein assay kit. Proteins were resolved using 10\% SDS-PAGE, transferred onto PVDF membranes (mass of protein loaded was $20 \mathrm{ug} / \mathrm{lane}$ ) and blocked with $5 \%$ skimmed milk for $1 \mathrm{~h}$ at room temperature. The membranes were incubated with primary antibodies (all dilutions 1:1,000) against TNC (cat. no. YT6187; ImmunoWay Biotechnology Company), E-cadherin (cat. no. 14472; Cell Signaling Technology, Inc.), N-cadherin (cat. no. 13116; Cell Signaling Technology, Inc.), VIM (cat. no. 5741; Cell Signaling Technology, Inc.), Slug (cat. no. 9585; Cell Signaling Technology, Inc.), protein kinase B (Akt; cat. no. 4691; Cell Signaling Technology, Inc.), phospho-(p)-Akt (cat. no. 4060; Cell Signaling Technology, Inc.), 70 kDa ribosomal protein S6 kinase 1 (P70S6K, cat. no. 2708; Cell Signaling Technology, Inc.), p-P70S6K (cat. no. 9204; Cell Signaling Technology, Inc.) and $\beta$-actin (cat. no. 4970; Cell Signaling Technology, Inc.) overnight at $4^{\circ} \mathrm{C}$. Following the primary incubation, membranes were incubated with secondary antibodies (dilution 1:20,000; cat. no. 926-32211; LI-COR Biosciences) for $1 \mathrm{~h}$ at room temperature. The membranes were scanned using an Odyssey infrared imaging system (LI-COR Biosciences), and semi-quantitative analysis was performed using ImageJ 1.8.0 software (National Institutes of Health).

Xenograft mouse model of NPC. Male BALB/c nude mice ( $\mathrm{n}=16 ; 5$ weeks old; $16-18 \mathrm{~g}$ ) were purchased from Beijing Weitonglihua Laboratory Animal Technology Co., Ltd (https://www.vitalriver.com). Mice were fed under specific pathogen-free conditions at constant temperature $\left(20-25^{\circ} \mathrm{C}\right)$ and humidity (40-70\%), with ad libitum access to water and food and a $12 \mathrm{~h}$ light/dark cycle. A total of 16 mice were randomly divided into four groups (shTNC 5-8F, shNC 5-8F, shTNC 6-10B and shNC 6-10B). Mice were anesthetized using isoflurane (Shenzhen biomart lifescience Co., Ltd, https://cdmocmo.ribobio.com/en/contact-us) with an induction concentration of $4-5 \%$ and a maintenance concentration of 1-3\% after 1 week of acclimatization. The right forelimb of nude mice was subcutaneously inoculated with TNC knockdown 5-8F cells, control 5-8F cells, TNC knockdown 6-10B cells and control $6-10 \mathrm{~B}$ cells. A total of $3.0 \times 10^{6}$ cells were injected per mouse, which was suspended in $200 \mu \mathrm{l}$ normal saline. Tumor grew on the fifth day, and the weight, tumor length (L) and width (W) were measured every other day. The maximum tumor size reached $15 \mathrm{~mm} 21$ days after cell injection. The maximum tumor volume was $0.755 \mathrm{~mm}^{3}$. Mice were sacrificed via cervical dislocation following anesthesia using 
$4-5 \%$ isoflurane. The tumors were surgically removed, and tumor volumes were calculated using the following equation: Tumor volume $=0.52 \times \mathrm{LxW}^{2}$. All animal experiments were approved by the Ethics Committee of Animal Experiments of Renmin Hospital of Wuhan University [Wuhan, China; approval no. 2020(421)], and performed in compliance with the laboratory animal management and guidelines.

Statistical analysis. Statistical analysis was performed using GraphPad Prism version 7.0 (GraphPad Software, Inc.). All experiments were performed in triplicate and data are presented as the mean \pm standard deviation. A two-tailed unpaired Student's t-test was used to compare differences between two groups, while one-way ANOVA followed by Tukey's post hoc test were used to compare difference between multiple groups. Fisher's exact two-tailed test was used to analyze TNC protein level difference between NPG and NPC tissues and its association with clinicopathological characteristics of NPC tissues. Pearson's correlation analysis was performed to analyze the correlation between genes. $\mathrm{P}<0.05$ was considered to indicate a statistically significant difference.

\section{Results}

TNC is upregulated in NPC tissues. To assess the transcriptional and expression levels of TNC in NPC, NPC gene datasets were downloaded from the GEO database. As presented in Fig. 1A, TNC transcription levels were significantly higher in the NPC tissues compared with the normal nasopharyngeal tissues, based on the GSE53819 $(\mathrm{P}=0.006)$ and GSE13597 $(\mathrm{P}=0.01)$ gene expression profiles. Fig. 1B presents TNC expression in 24 NPC metastasis tissues and 24 NPC non-metastasis tissues. The results demonstrated that TNC mRNA levels were significantly higher in NPC metastasis tissues compared with non-metastasis tissues $(\mathrm{P}=0.033)$. The distribution of TNC mRNA levels in NPC gene chip is presented in Table I. Representative images of TNC staining in NPC and NPG tissues with classification of '-', '+', '++' and ' +++ ' are presented in Fig. 1C. Tissues graded as ' - ' was considered as the negative expression TNC group, while ' + ', '++' and '+++' were considered as the positive TNC expression group. The results demonstrated that $87.8 \%$ of NPC tissues and $12.9 \%$ of NPG tissues positively expressed TNC $(\mathrm{P}<0.0001$; Table II).

To further investigate the clinicopathological significance of TNC in NPC, the association between TNC expression and the clinicopathological characteristics of patients with NPC was analyzed. As presented in Table III, TNC protein expression was not significantly associated with age and sex of patients with NPC ( $>>0.05)$. However, TNC expression was significantly associated with $\mathrm{T}$ staging and $\mathrm{N}$ staging. The results demonstrated that patients at T3-T4 stages had higher TNC protein expression levels than those at T1-T2 stages $(\mathrm{P}=0.001)$. In addition, patients at N2-N3 stages had higher TNC protein expression levels than those at N0-N1 stages $(\mathrm{P}<0.0001)$. $\mathrm{T}$ staging represents the size and scope of invasion of NPC, while N staging refers to the involvement of regional lymph nodes (29). Taken together, these results suggest that TNC is associated with the malignant progression of NPC.
Table I. Distribution of TNC mRNA expression in nasopharyngeal carcinoma gene chip.

\begin{tabular}{lccc}
\hline Dataset & $\begin{array}{c}\text { Number of } \\
\text { samples }\end{array}$ & $\begin{array}{c}\text { TNC mRNA } \\
\text { expression }\end{array}$ & P-value \\
\hline GSE53819 & & 7.082 & $0.006^{\mathrm{b}}$ \\
NPC tissue & 18 & 6.347 & \\
$\quad$ Normal tissue & 18 & & $0.010^{\mathrm{b}}$ \\
GSE13597 & & 6.867 & \\
NPC tissue & 25 & 5.258 & \\
Normal tissue & 3 & & $0.033^{\mathrm{a}}$ \\
GSE103611 & & 1.943 & \\
NPC M tissue & 24 & 1.826 & \\
NPC NM tissue & 24 & & \\
\hline
\end{tabular}

${ }^{\text {a }} \mathrm{P}<0.05$; ${ }^{\text {b }} \mathrm{P}<0.01$. TNC, tenascin-C; NPC, nasopharyngeal carcinoma; $\mathrm{M}$, metastasis; NM, non-metastasis.

WGCNA and determination of the co-expression module of $T N C$. WGCNA is based on two hypotheses: i) Genes with similar expression patterns may be functionally relates, co-regulated or in the same pathway and ii) gene networks conform to a scale-free distribution (22). Based on these two points, the gene network can be divided into different modules according to the similarity of expression to find the key genes (30-32). Gene expression data were analyzed to remove outliers, and no samples were excluded. A total of 36 samples were included in the WGCNA (Fig. S1). The samples were grouped into different clusters in the sample dendrogram and the trait heatmap is presented in Fig. S2A. The scale $\mathrm{R}^{2}$ value and power value $(\beta)$ decide the independence and average connectivity (22). Fig. S2B and C demonstrate that when $\beta=7$, the scale was $R^{2}=0.89$. Therefore, soft thresholding with $\beta=7$ was used to achieve and analyze recognizable co-expression gene modules in datasets. As a result, 15 gene co-expression modules were identified in different colors based on a TOM-based dissimilarity measure (Fig. S2D). The interactions of these co-expression modules were analyzed via Pearson's correlation coefficient, and every module was independent of each other (Fig. S2E). A higher degree of module correlation is indicated by a darker background. The first principal component gene in each module was identified as the feature vector gene representing the overall gene expression level (Fig. 2A). Red squares along the diagonal represent the meta-modules. Module eigengenes were clustered in the dendrogram (Fig. S3A). Modules below the red line indicate that the correlation was $>0.8$, and these were merged. Fig. $2 \mathrm{~B}$ presents the association between the module eigengenes and TNC expression. The light cyan module was closely associated with TNC expression $(\mathrm{r}=0.56 ; \mathrm{P}=0.005)$. Fig. $\mathrm{S} 3 \mathrm{~B}$ presents the heatmap of the expression volume of the light cyan module and the histogram of the feature vector gene. The expression of the feature vector gene was highly correlated with the expression of genes in the entire module. The internal connectivity was calculated, and the module membership of each gene was used to identify hub genes that were highly correlated with 

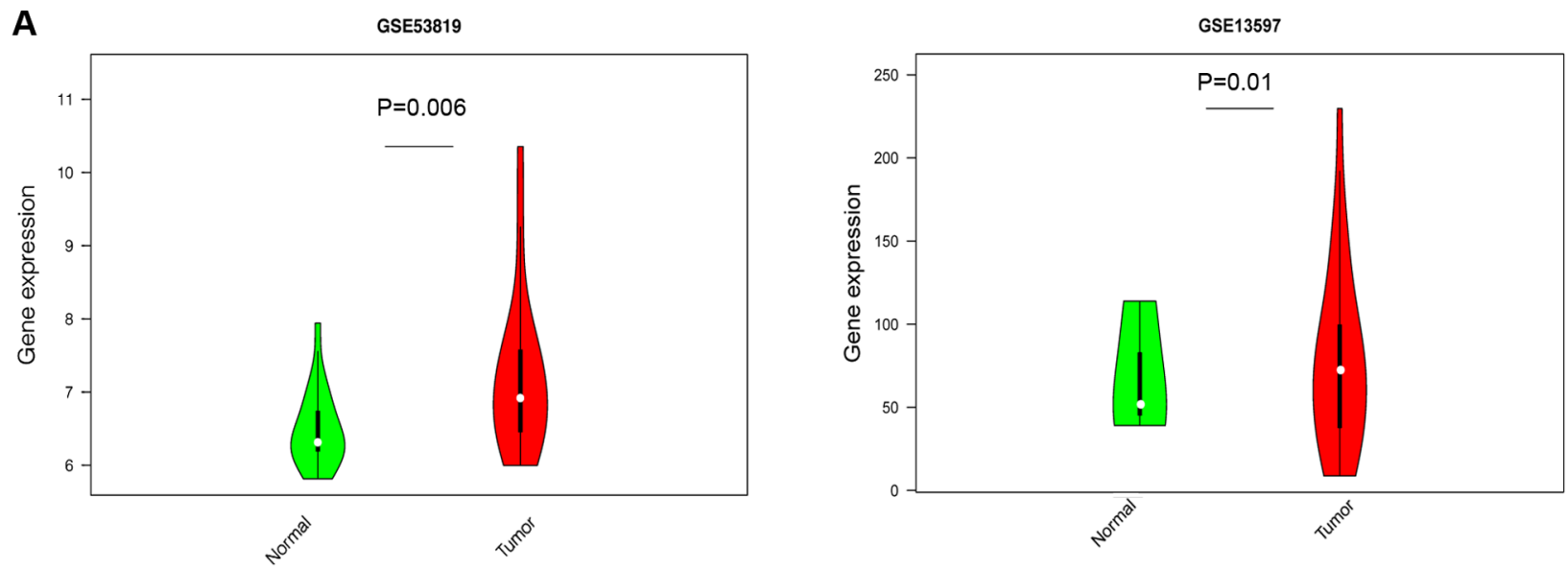

B

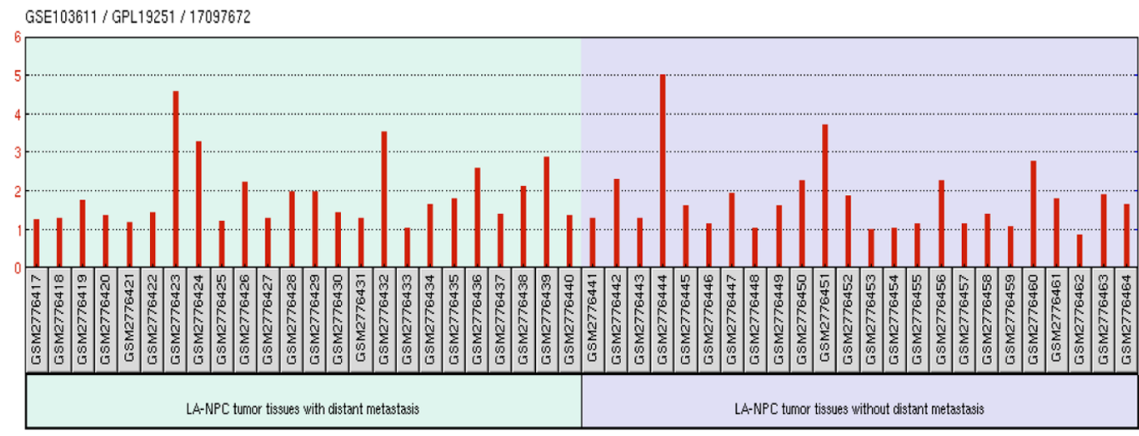

" Expression value
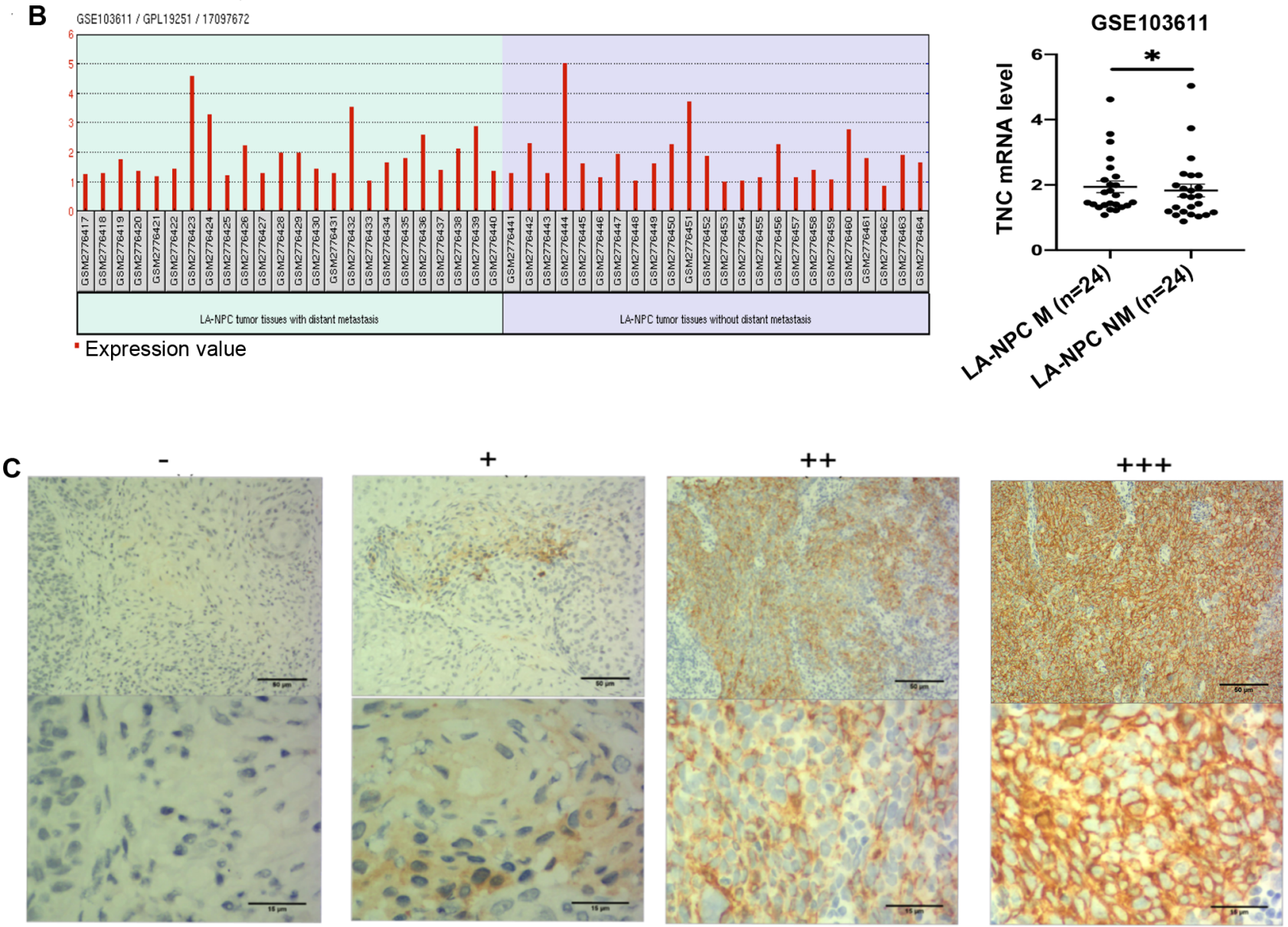

Figure 1. TNC expression is upregulated in NPC tissues. (A) Transcription levels of TNC in NPC tissues and normal nasopharyngeal tissues in the GSE13597 and GSE53819 datasets. (B) Transcription levels of TNC in tissues of the GSE103611 dataset. (C) Immunohistochemical staining of TNC in clinical NPC and NPG tissues. Tissues were classified as,,-+++ and +++ . Brown staining represents TNC protein expression, while blue staining represents the nuclei. TNC, tenascin-C; NPC, nasopharyngeal carcinoma; NPG, nasopharyngitis. LA-NPC, locally advanced nasopharyngeal carcinoma; '-', negative expression of TNC; '+', '++' and '+++', positive expression of TNC; '-', '+', low expression of TNC; '++' and '+++', high expression of TNC. 'P<0.05.

TNC expression. The internal connectivity measures the position of the gene in the module, and the module membership indicates which module the gene belongs to. The intermodular connectivity was significantly correlated with the module membership ( $\mathrm{P}=0.00001)$ (Fig. S4). There were three criteria to screen for hub genes, including a gene and specified module significance of $>0.2$, modular membership value of $>0.8$ and $\mathrm{q}<0.01$. A total of 52 genes that met the above criteria were identified. Fig. $2 \mathrm{C}$ presents the overlapping topological heatmap of these hub genes. In the heatmap, the darker the color, the higher the degree of topological overlap.

GO and KEGG enrichment analyses for the hub genes in the light cyan module. To demonstrate the functions of hub genes in the light cyan module, GO and KEGG enrichment analyses in the Molecular Signatures Database were performed. The 
Table II. Statistical analysis of TNC expression in NPC tissues (tissue microarray).

\begin{tabular}{|c|c|c|c|c|c|c|c|}
\hline \multirow[b]{3}{*}{ Group } & \multicolumn{4}{|c|}{ TNC expression (n) } & \multirow{3}{*}{$\frac{\text { Total }}{150}$} & \multirow[b]{3}{*}{ Positive rate, $\%$} & \multirow[b]{3}{*}{ P-value } \\
\hline & \multicolumn{2}{|c|}{ Negative } & \multicolumn{2}{|c|}{ Positive } & & & \\
\hline & - & + & ++ & +++ & & & \\
\hline NPG tissue & 31 & 4 & 0 & 0 & 35 & 12.9 & $<0.0001$ \\
\hline NPC tissue & 14 & 29 & 46 & 26 & 115 & 87.8 & \\
\hline
\end{tabular}

TNC, tenascin-C; NPC, nasopharyngeal carcinoma; NPG, nasopharyngitis.

Table III. Association between TNC expression and the clinicopathological characteristics of patients with NPC.

\begin{tabular}{|c|c|c|c|c|c|}
\hline \multirow[b]{2}{*}{ Characteristic } & \multirow{2}{*}{$\begin{array}{l}\begin{array}{c}\text { Number of } \\
\text { patients }\end{array} \\
\text { Total, } 115\end{array}$} & \multicolumn{2}{|c|}{ TNC expression (n) } & \multirow[b]{2}{*}{ High expression rate, $\%$} & \multirow[b]{2}{*}{ P-value } \\
\hline & & Low & High & & \\
\hline Age, years & & & & & 0.703 \\
\hline$<50$ & 51 & 18 & 33 & 64.7 & \\
\hline$>50$ & 64 & 25 & 39 & 60.9 & \\
\hline \multicolumn{6}{|l|}{ Sex } \\
\hline Male & 78 & 29 & 47 & 60.3 & 0.842 \\
\hline Female & 37 & 14 & 25 & 67.6 & \\
\hline $\mathrm{T}$ stage & & & & & $0.001^{\mathrm{a}}$ \\
\hline $\mathrm{T} 1-\mathrm{T} 2$ & 39 & 23 & 16 & 41.0 & \\
\hline $\mathrm{T} 3-\mathrm{T} 4$ & 76 & 20 & 56 & 73.7 & \\
\hline $\mathrm{N}$ stage & & & & & $<0.0001^{\mathrm{b}}$ \\
\hline N0-N1 & 52 & 32 & 20 & 38.5 & \\
\hline N2-N3 & 63 & 11 & 52 & 82.5 & \\
\hline
\end{tabular}

${ }^{\mathrm{a}} \mathrm{P}<0.01$; ${ }^{\mathrm{P}} \mathrm{P}<0.001$. '-' and '+' were classified as low TNC expression, while '++' and '+++' were classified as high TNC expression. TNC, tenascin-C; NPC, nasopharyngeal carcinoma.

top 10 terms of biological process (BP), cellular component (CC) and molecular function (MF) in GO analysis are presented in Fig. 3A-C. Hub genes were primarily enriched in the 'locomotion', 'cell motility', 'biological adhesion', 'enzyme-linked receptor protein signaling pathway', 'regulation of cellular component movement', 'embryo development', 'cellular component morphogenesis', 'positive regulation of locomotion', 'transmembrane receptor protein tyrosine kinase signaling pathway' and 'extracellular structure organization' in BP (Fig. 3A). In CC, the terms that hub genes were primarily enriched in included 'endoplasmic reticulum', 'anchoring junction', 'cell junction', 'Golgi apparatus', 'cell-substrate junction', 'cell surface', 'endoplasmic reticulum lumen', 'extracellular matrix', 'cell leading edge' and 'ruffle' (Fig. 3B). In MF, hub genes were primarily enriched in the terms 'signaling receptor binding', 'protein-containing complex binding', 'growth factor binding', 'cell adhesion molecular binding', 'integrin binding', 'cytokine binding', 'platelet-derived growth factor receptor binding', 'fibroblast growth factor binding', 'extracellular matrix binding' and 'actin dependent ATPase activity'
(Fig. 3C). The hub genes were enriched in the KEGG pathway of 'focal adhesion', 'regulation of actin cytoskeleton', 'ECM receptor interaction', 'pathways in cancer', 'arrhythmogenic right ventricular cardiomyopathy arch' and 'small cell lung cancer' (Fig. 3E). Also, the hub genes in the light cyan module were enriched for Hallmark gene sets using the Molecular Signatures database. There were 31 Hallmark gene sets enriched, and the top 10 are presented in Fig. 3D, amongst which EMT was the most enriched.

TNC regulates EMT progression in NPC cells. Based on the results of WGCNA and the hallmark enrichment analysis, it is suggested that TNC may activate EMT to promote NPC malignant progression by altering the components of the ECM and influencing cell adhesion. Consequently, stable TNC knockdown in NPC cells was established, which was verified via western blot and RT-qPCR analyses (Fig. 4A and B). The expression levels of the EMT-related markers, VIM, CDH2, Slug and CDH1 were detected in the knockdown and control cells via western blot and RT-qPCR analyses (Fig. 4C and D). 
A

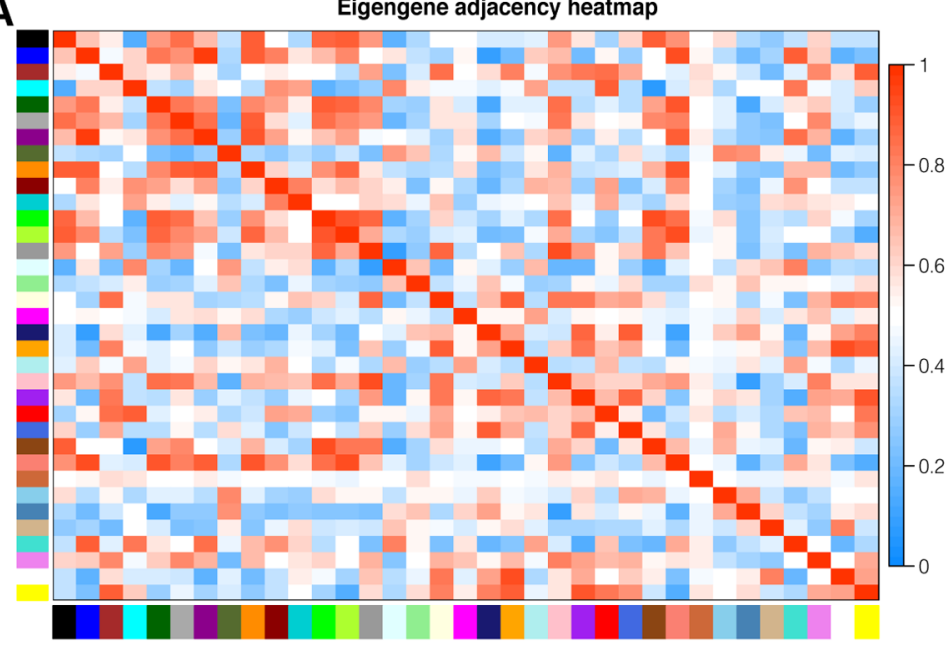

C

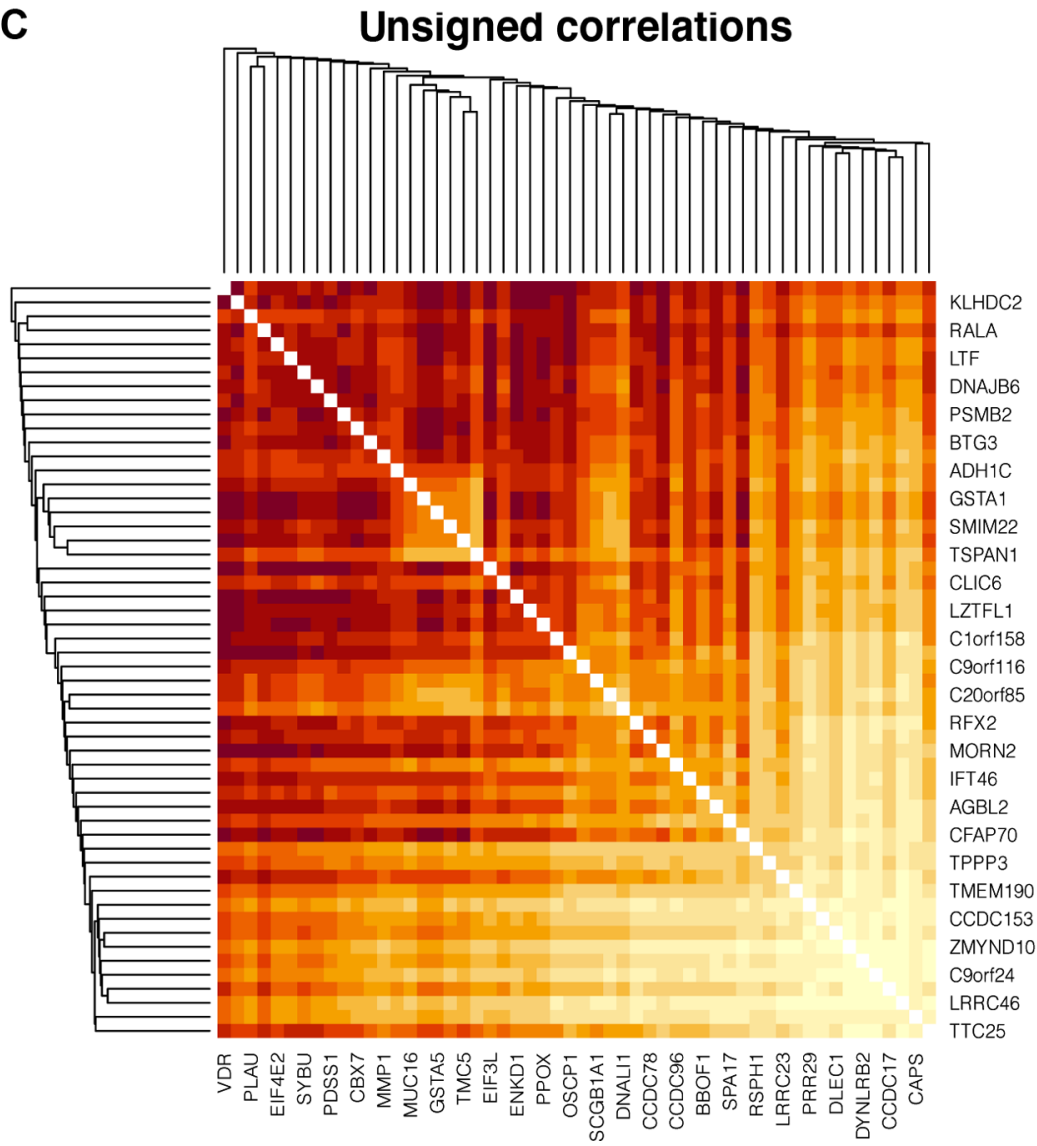

B Module-TNC relationships

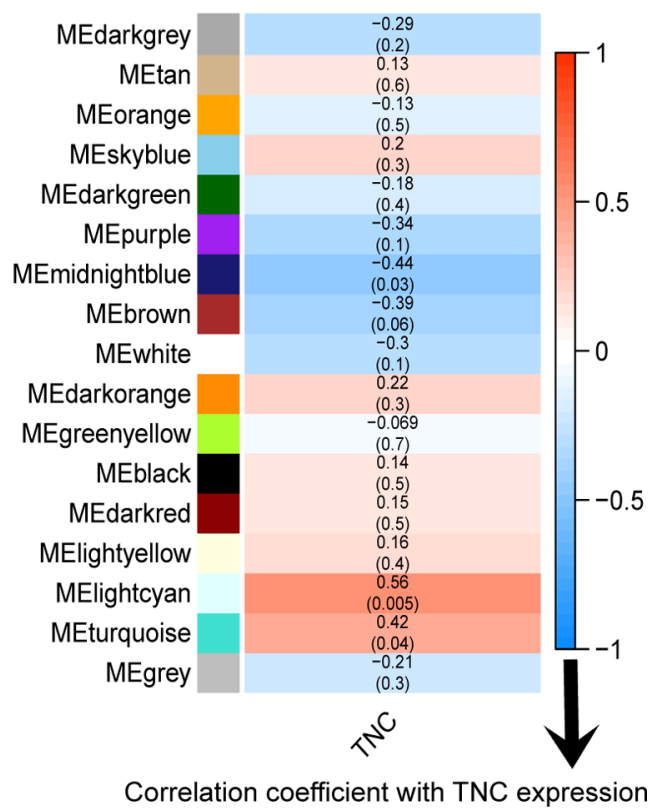

Figure 2. Weighted gene co-expression network analysis. (A) Heatmap of eigengene adjacency. Red squares along the diagonal represent the meta-modules. (B) Correlation between module eigengenes and TNC. Each row corresponds to a module eigengene and columns represent TNC expression. Each cell contains the correlation coefficient and P-value; the light cyan module was selected for further analysis. (C) Topological overlapping heatmap of these hub genes. TNC, tenascin-C. In the heatmap, the darker the color, the higher the degree of topological overlap.

The results demonstrated a negative association between $\mathrm{TNC}$ expression and the epithelial phenotype, and a positive association between TNC expression and the mesenchymal phenotype. Collectively, these results suggest that suppression of TNC inhibits EMT progression of NPC cells.

TNC knockdown inhibits proliferation, migration and invasion of NPC cells. The role of TNC in the proliferation and metastasis of NPC cells was assessed. The CCK-8 and EdU assays were performed to assess cell proliferation. The results of the CCK- 8 assay demonstrated that TNC knockdown significantly decreased the proliferation of both $5-8 \mathrm{~F}$ and $6-10 \mathrm{~B}$ cells $(\mathrm{P}<0.05)$ (Fig. $5 \mathrm{~A})$. In the EdU assay, TNC knockdown suppressed cell proliferation, with lower proportions of EdU-positive cells in both cell lines (Fig. 5B). 
A
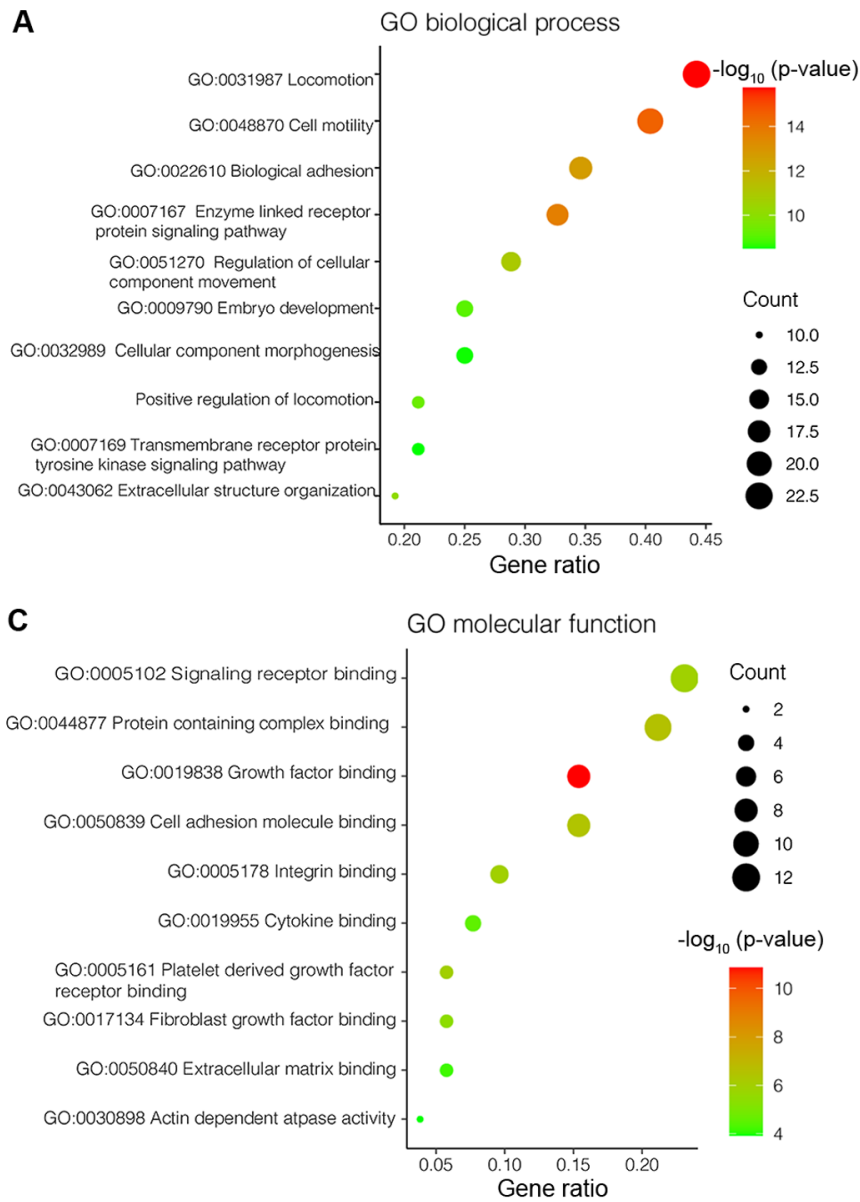

$\mathrm{E}$

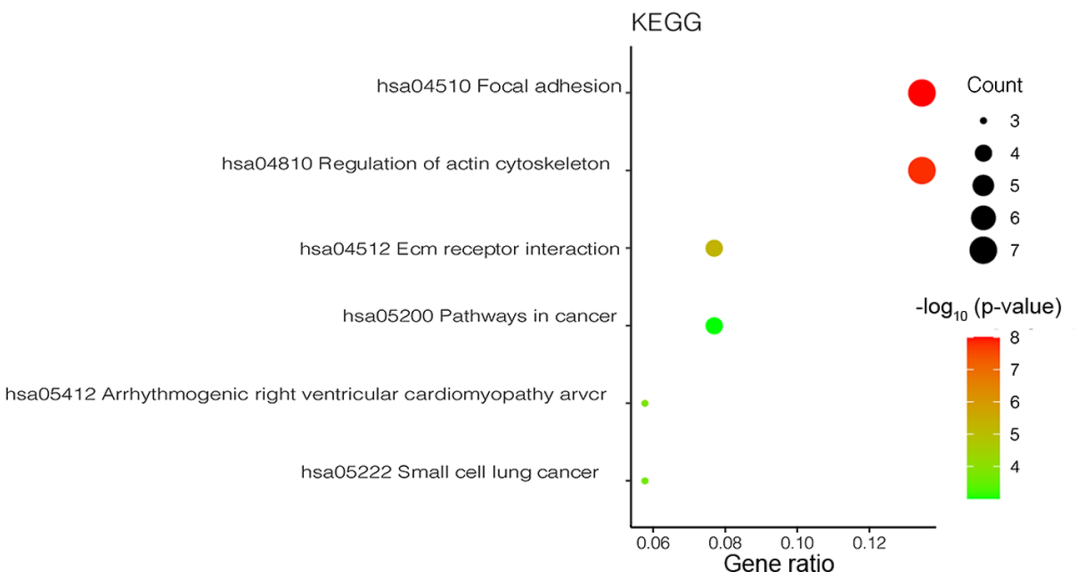

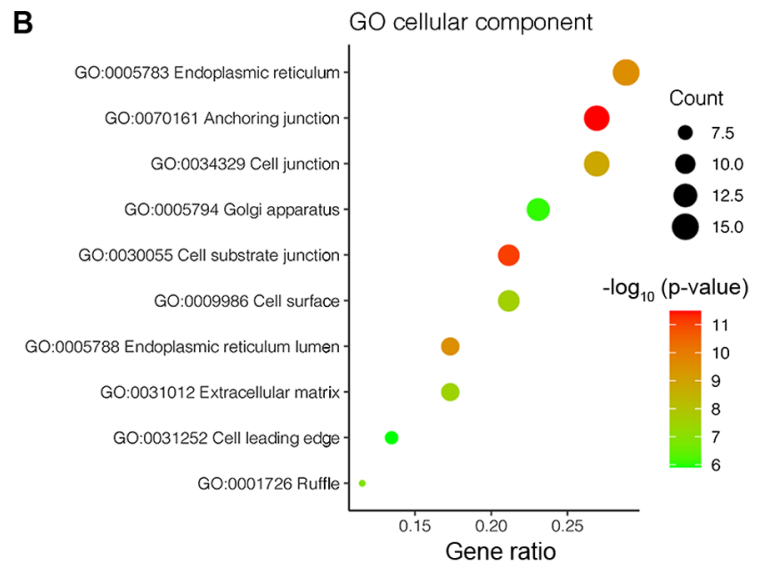

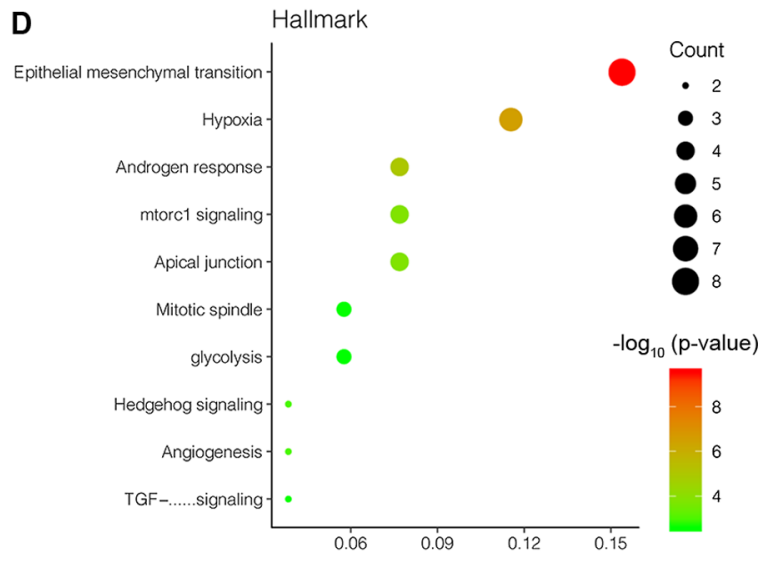

Figure 3. Enrichment analysis of genes co-expressed with TNC. GO functional term enrichment analysis of the hub genes in the light cyan module, including (A) biological process, (B) cellular component and (C) molecular function analyses. (D) The Hallmark gene sets of epithelial-to-mesenchymal transition was enriched. (E) KEGG signaling pathway enrichment analysis of the hub genes in the light cyan module. TNC, tenascin-C; GO, Gene Ontology; KEGG, Kyoto Encyclopedia of Genes and Genomes.

The effect of TNC on NPC cell migration and invasion was determined via the wound healing and Transwell invasion and migration assays. As presented in Fig. 5C, wound closure was notably higher in the control group compared with the TNC knockdown group, which suggests that TNC knockdown inhibited cell migration. In the Transwell migration assay, TNC knockdown significantly decreased the number of migratory cells compared with the control group $(\mathrm{P}<0.05$; Fig. 5D). Similarly, in the invasion assay, TNC knockdown decreased the number of invasive cells in the experimental group compared with the control group. Taken together, these results suggest that TNC knockdown inhibits the proliferation, migration and invasion of NPC cells.

TNC knockdown inhibits the mTOR signaling pathway in NPC cells. To investigate the potential mechanism by which TNC expression promotes EMT and cell proliferation in NPC cells, the expression of proteins associated with the mTOR signaling pathway was detected via western blot analysis in NPC cells transfected with shNC or shTNC. The results demonstrated that TNC knockdown significantly decreased the expression levels of p-P70S6K and p-AKT in both 5-8F and 6-10B cells 
A
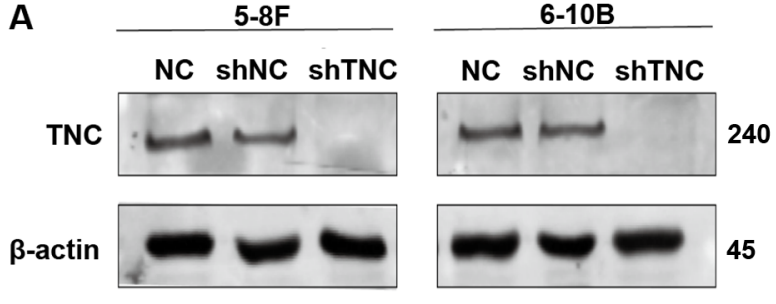

B
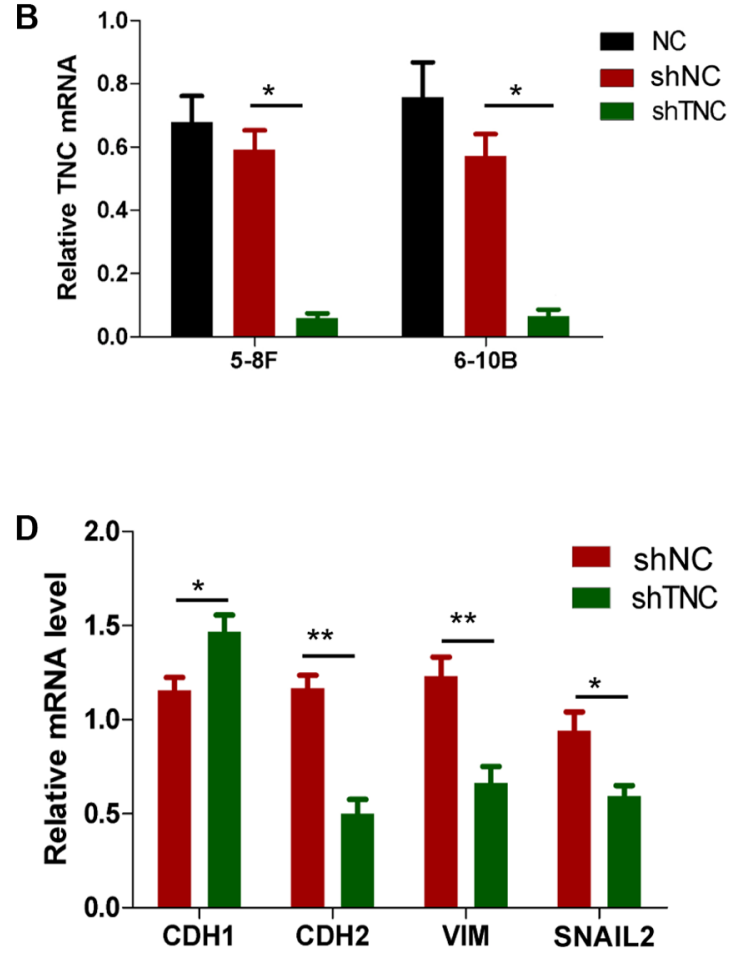

C

240
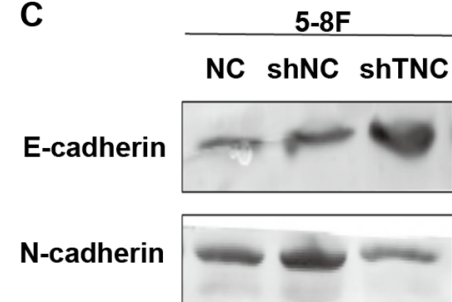

N-cadherin
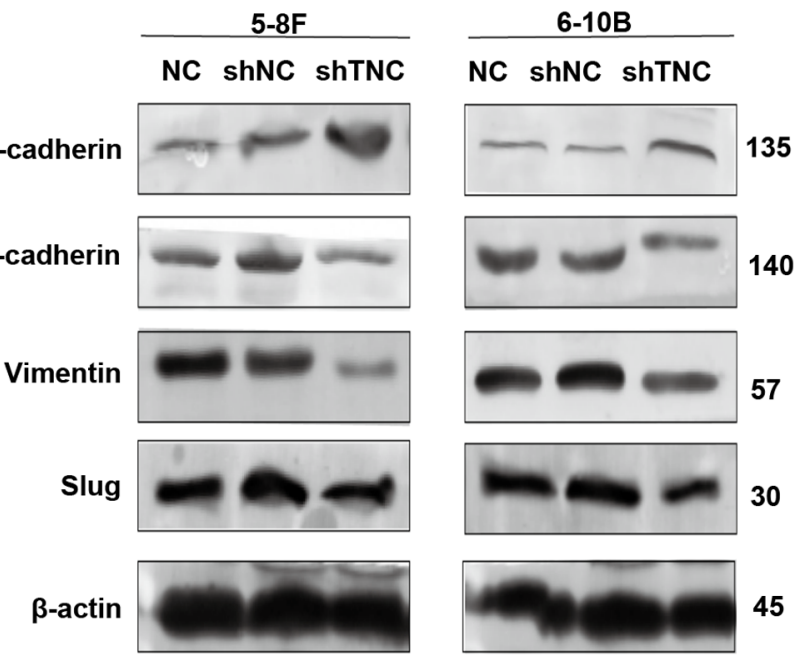

135
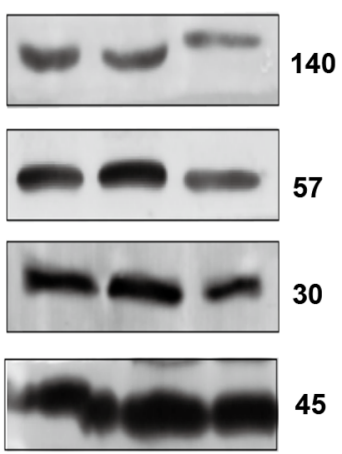

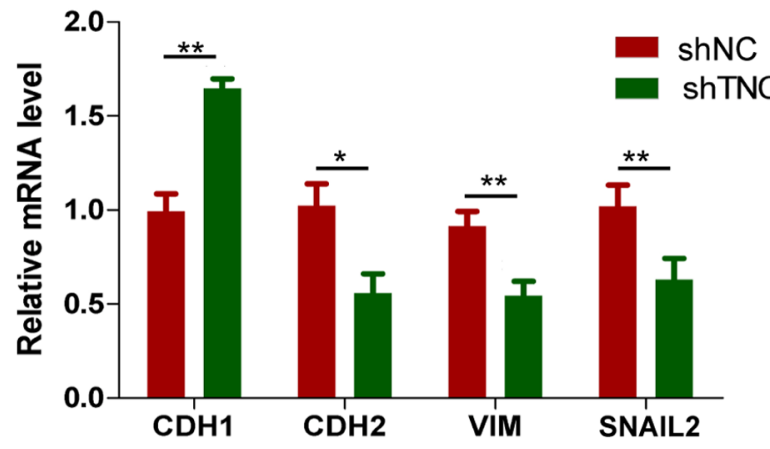

Figure 4. TNC promotes malignant progression of NPC by inducing EMT. (A) Western blot and (B) RT-qPCR analyses were performed to detect the expression levels of TNC in 5-8F and 6-10B cells following lentiviral transfection. (C) Western blot and (D) RT-qPCR analyses were performed to detect the expression levels of the EMT-related markers in stable TNC-knockdown 5-8F and 6-10B cells. Data are presented as the mean \pm standard deviation ( $=3$ ). ${ }^{*}<0.05$; ${ }^{* *} \mathrm{P}<0.01$. TNC, tenascin-C; NPC, nasopharyngeal carcinoma; EMT, epithelial-to-mesenchymal transition; RT-qPCR, reverse transcription-quantitative PCR; $\mathrm{NC}$, negative control; sh, short hairpin; CDH, cadherin; VIM, vimentin; SNAIL2, snail family transcriptional repressor 2; NC, negative control.

$(\mathrm{P}<0.05$; Fig. 6A and B). Collectively, these results suggest that TNC promotes EMT, at least partially via the mTOR signaling pathway.

Effect of TNC expression on tumorigenesis in vivo. To determine whether TNC expression affected tumor growth in vivo, a xenograft mouse model was established by injecting shTNC or shNC NPC cells into nude mice. The results demonstrated that injection of cells in which TNC expression was knocked down reduced tumor growth in the xenograft mouse model compared with mice injected with shNC-transfected 5-8F and 6-10B cells (Fig. 7A-C). In addition, there were no significant differences in the weight of mice between the different groups (Fig. 7D). Taken together, these findings suggest that TNC expression regulates tumor growth in vivo.

\section{Discussion}

The results of the present study demonstrated that TNC was upregulated in NPC tissues. In addition, TNC knockdown inhibited proliferation, migration, invasion and EMT of NPC cells, suggesting that TNC may promote cell proliferation and EMT, resulting in the malignant progression of NPC. Furthermore, the expression of proteins associated with the mTOR signaling pathway decreased in TNC-knockdown NPC cells compared with the control group. Taken together, these results suggest that TNC promotes EMT progression and mTOR signaling in NPC.

TNC expression is associated with neoplasia of different organs, as well as the development of fetal tissue, which may serve as a biomarker or predictor of tumor invasion and metastasis in different types of cancer (13,33-36). However, to the best of our knowledge, there are no studies investigating the role of TNC in NPC. In the present study, TNC gene transcription levels in NPC datasets obtained from GEO were assessed, and the results demonstrated that TNC expression was significantly higher in NPC tissues compared with normal tissues $(\mathrm{P}<0.05)$. In addition, TNC expression was significantly higher in NPC metastasis tissues compared with non-metastasis tissues $(\mathrm{P}<0.05)$. To verify these results, TNC expression levels in NPC tissues were assessed via IHC analysis in a TMA. The results demonstrated that TNC gene expression was higher in 
A
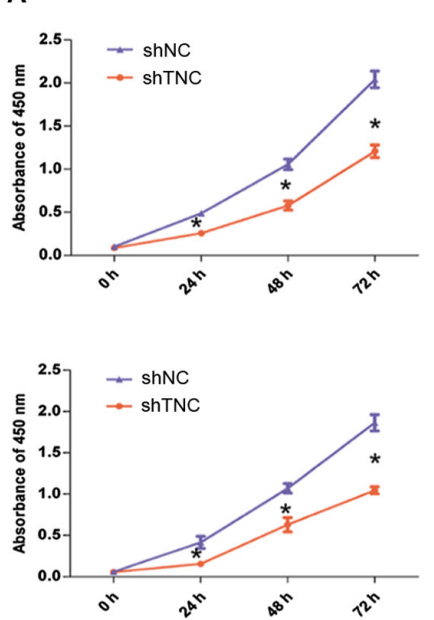

C

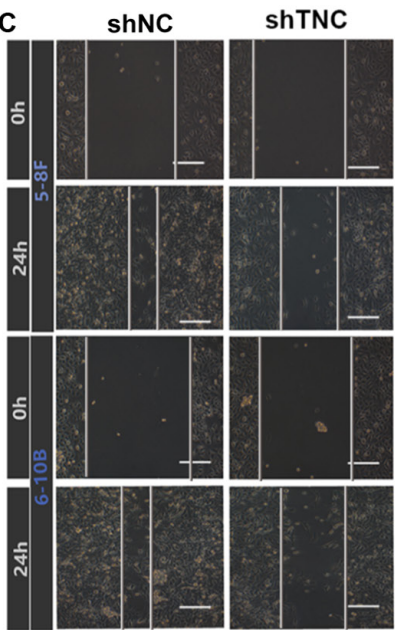

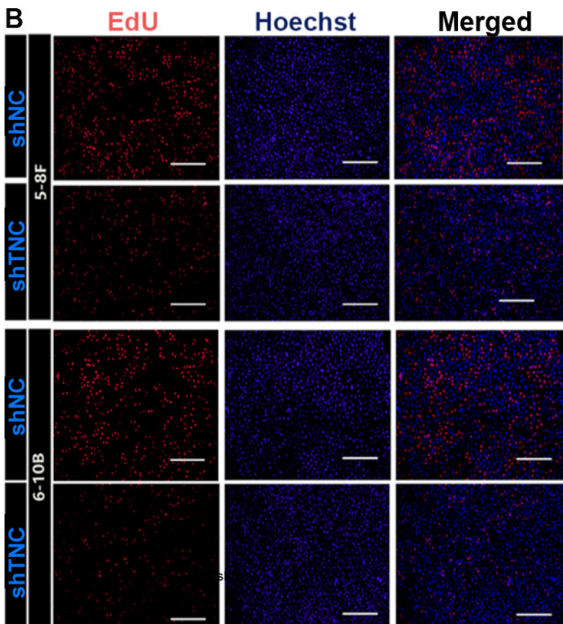
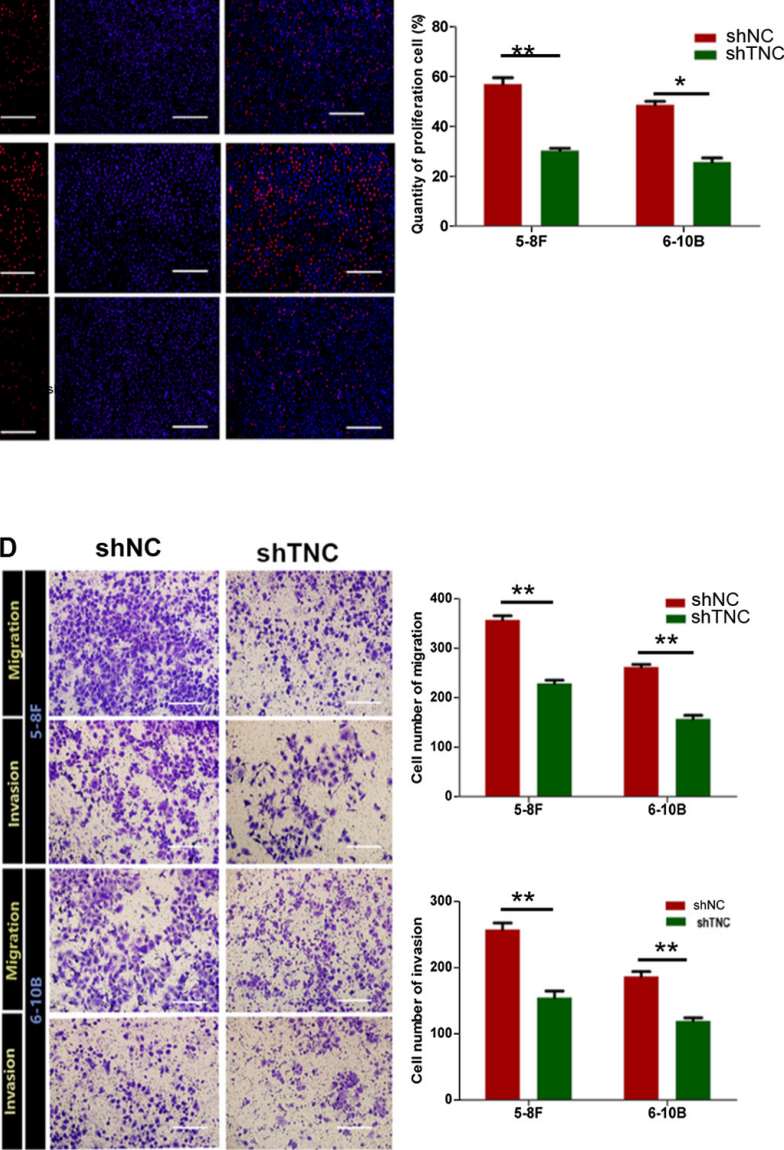

Figure 5. TNC knockdown inhibits proliferation, migration and invasion of NPC cells. The effect of TNC knockdown on the proliferation of 5-8F and 6-10B cells was detected using (A) Cell Counting Kit- 8 (cell numbers at 0,24 and $72 \mathrm{~h}$ between shNC $5-8 \mathrm{~F}$ and shTNC 5-8F groups, shNC 6-10B and shTNC 6-10B groups were compared, respectively.) and (B) EdU assays. (C) The wound healing assay was performed to assess the migratory ability of 5-8F and 6-10B cells transfected with shTNC. The open wound area after $24 \mathrm{~h}$ was expressed relative to the area at the start of the assay. (D) Transwell migration and (E) invasion assays of TNC knockdown 5-8F and 6-10B cells. Cells that had migrated to the bottom chamber were stained with crystal violet. Data are presented as the mean \pm standard deviation $(n=3)$ and normalized to the respective control cells. ${ }^{*} \mathrm{P}<0.05$; ${ }^{* *} \mathrm{P}<0.01$. TNC, tenascin-C; NPC, nasopharyngeal carcinoma; sh, short hairpin; NC, negative control.

A

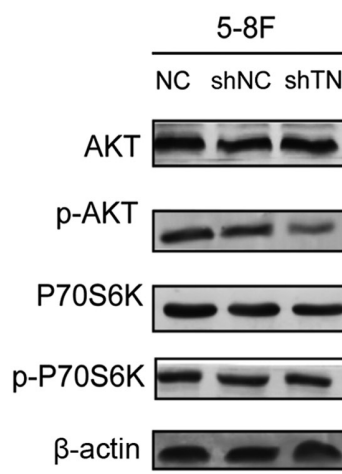

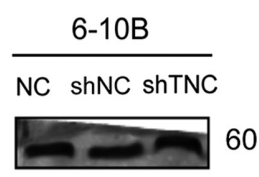
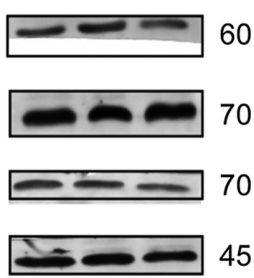
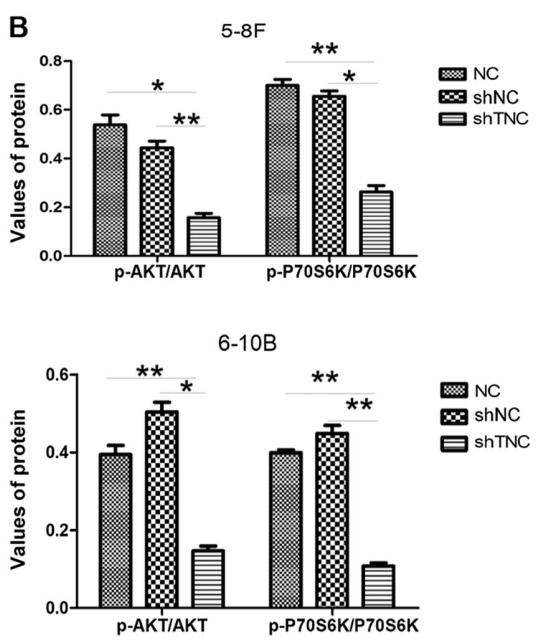

Figure 6. TNC knockdown inhibits the mTOR signaling pathway in NPC cells. (A) The expression levels of AKT, p-AKT,P70S6K, p-P70S6K in TNC-knockdown cells. (B) Densitometry analysis of the p-AKT/AKT and p-P70S6K/P70S6K ratios were semi-quantified and are presented as the mean \pm standard deviation. ${ }^{\text {"P }}<0.05$; ${ }^{* *} \mathrm{P}<0.01$. TNC, tenascin-C; NPC, nasopharyngeal carcinoma; p-, phospho; P70S6K, 70 kDa ribosomal protein S6 kinase 1; NC, negative control; sh, short hairpin; NC, negative control. 
A

5-8F

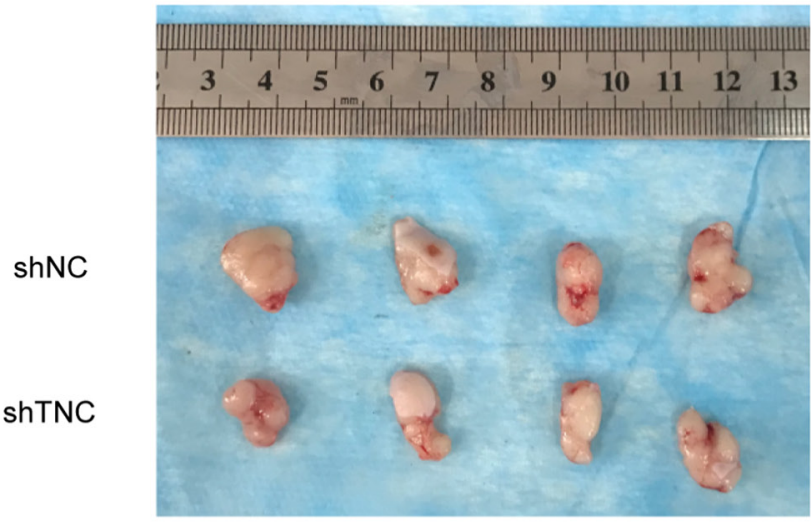

$6-10 B$

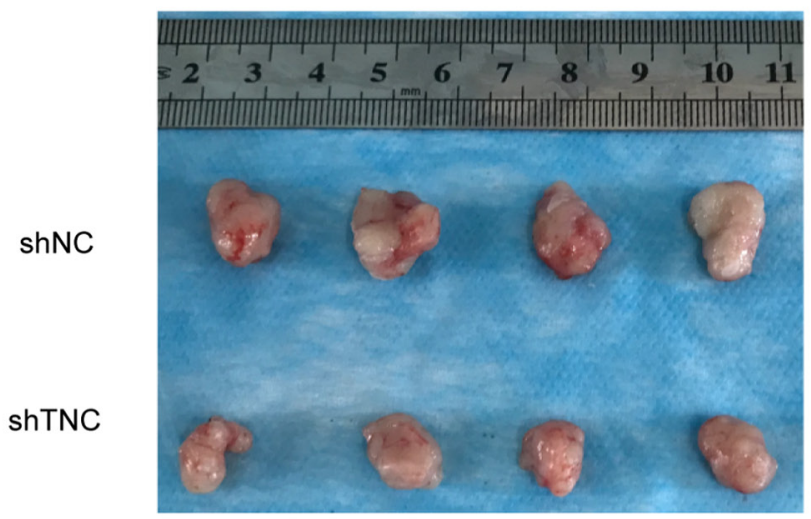

D

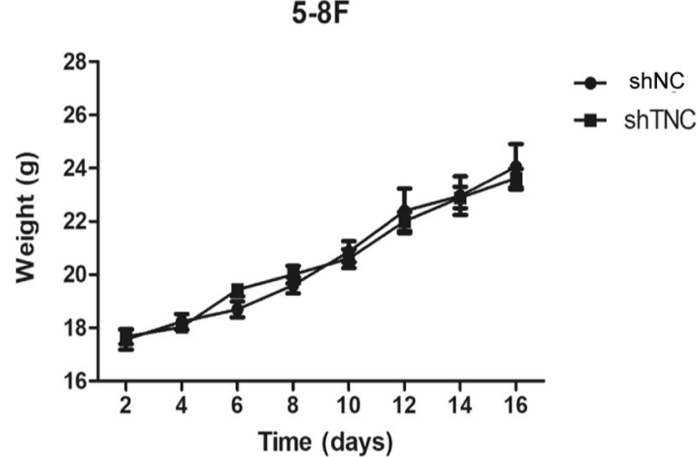

B
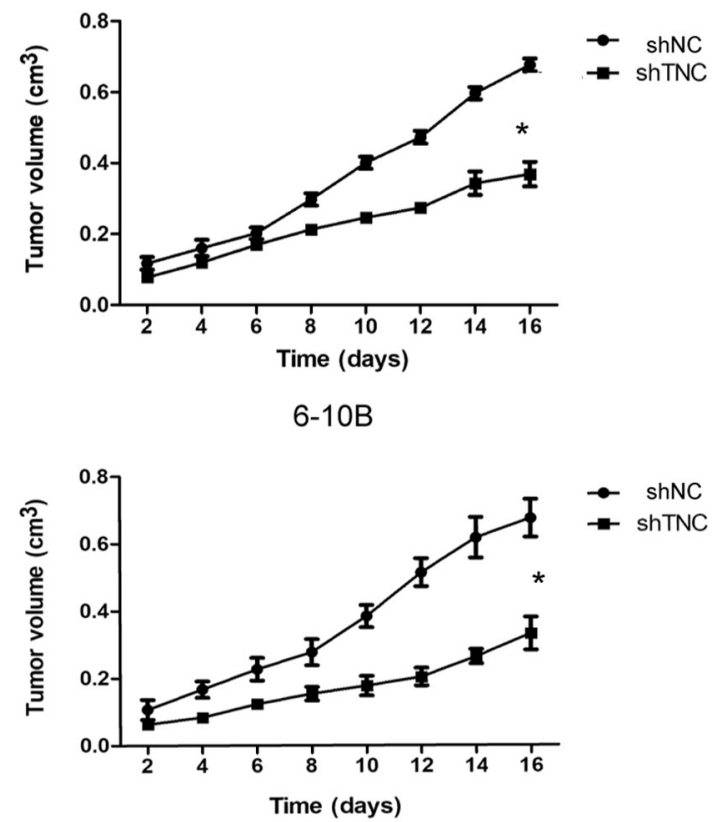

C

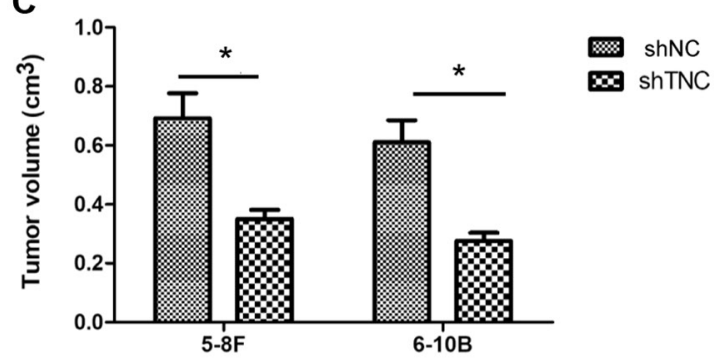

6-10B

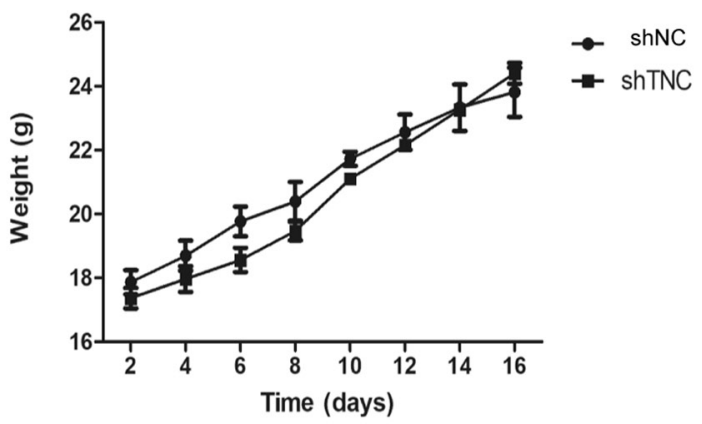

Figure 7. Effects of TNC expression on tumor growth in xenografts. (A) Representative images of tumors that were removed from xenografts. (B) Tumor growth in the mice injected with the different cell lines. Tumor volume of different days in mice injected with shNC 5-8F and shTNC 5-8F groups, shNC 6-10B and shTNC 6-10B groups were compared, respectively. (C) Histogram presenting the average volume of tumors. (D) There were no significant differences in the average weight of the mice. " $\mathrm{P}<0.05$. TNC, tenascin- $\mathrm{C}$; sh, short hairpin; $\mathrm{NC}$, negative control.

NPC tissues compared with NPG tissues. In addition, TNC expression was associated with $\mathrm{T}$ staging and $\mathrm{N}$ staging of patients with NPC. Collectively, these results suggest that TNC plays an important role in NPC progression and metastasis.

The effect of TNC expression on the biological functions of NPC cells were assessed both in vitro and in vivo. TNC knockdown inhibited proliferation, migration and invasion of NPC cells. In addition, TNC knockdown inhibited tumor growth in vivo. These results suggest that TNC promotes NPC cell proliferation. To further investigate the potential mechanism by which TNC promotes NPC cell proliferation, WGCNA was performed followed by GSEA to identify the gene sets associated with TNC expression in the microarray data from the GEO datasets. KEGG and GO enrichment 
analyses demonstrated that the hub genes in the key modules were primarily associated with 'ECM' and 'cell adhesion'. GSEA demonstrated that there were more EMT-associated gene sets upregulated in the TNC high expression group compared with the TNC low expression group. The expression of key proteins associated with EMT was assessed via RT-qPCR and western blot analyses. Consistent with the findings of GSEA, TNC knockdown decreased the expression of EMT-related markers. In addition, the mTOR complex (mTORC)1 signaling pathway was enriched in the Hallmark results. The PI3K/Akt/mTOR signaling pathway is a critical pathway involved in tumorigenesis (37). It has been reported that mTOR regulates cell motility, proliferation and metabolism (38). The mTOR pathway includes the mTORC1 and mTORC2 complexes, which are intricately associated with tumor cell proliferation and tumor survival (39). P-P70S6K and p-Akt expression are the downstream effectors of mTORC1 and mTORC2, respectively (40). In addition, the $\mathrm{PI} 3 \mathrm{~K} / \mathrm{Akt} / \mathrm{mTOR}$ signaling pathway serves an important role in EMT $(41,42)$. $\beta$-catenin is a crucial regulator of EMT $(43)$. p-Akt can phosphorylate GSK-3 $\beta$ at Ser9, inhibiting its kinase activity, which downregulates both $\mathrm{N}-\beta$-catenin and $\mathrm{T}-\beta$-catenin expression (44). Thus, p-P70S6K and $\mathrm{p}-\mathrm{Akt}$ expression were detected in NPC cells. The results of the present study demonstrated that TNC knockdown inhibited p-P70S6K and p-Akt expression. Taken together, these results suggest that TNC gene expression promotes EMT and the mTOR signaling pathway in NPC cells.

In conclusion, the results of the present study demonstrated that TNC expression was upregulated in NPC tissues compared with normal tissues. In addition, TNC knockdown in NPC cells inhibited NPC cancer cell proliferation, migration, invasion and EMT. Furthermore, TNC knockdown inhibited tumor growth in vivo. TNC knockdown also downregulated the mTOR pathway. Taken together, these results suggest that TNC promotes cell proliferation, EMT and the mTOR signaling pathway in NPC. Thus, TNC may function as an oncogene in NPC cells, and TNC suppression may be an innovative angle for the clinical treatment of NPC.

There were two main novelties of the present study. On one hand, bioinformatics analysis was combined with basic experiments as experimental methods. The transcription level of TNC in NPC and its association with metastasis of NPC cells were investigated via bioinformatics analysis, and these results were verified via IHC analysis. Similarly, the function and mechanism of TNC in NPC cells were predicted via WGCNA and GSEA, and these results were verified via cell experiments. Combining bioinformatics analysis and basic experiments made the research more efficient and cost-effective. To the best of our knowledge, the present study was the first to investigate the role of TNC in NPC. In the present study, IHC analysis and in vivo and in vitro experiments were performed to determine TNC expression in NPC and its biological function, which provides a basis for further investigation on the role of TNC in the treatment of NPC.

However, the present study is not without limitations. For example, the extent of involvement of the mTOR pathway was not determined. This will be assessed in prospective studies to further determine how TNC regulates the mTOR signaling pathway in NPC.

\section{Acknowledgements}

Not applicable.

\section{Funding}

The present study was supported by the National Natural Science Foundation of China (grant nos. 81372880) and the Guidance fund of the Renmin Hospital of Wuhan University (grant no. RMYD2018Z12).

\section{Availability of data and materials}

The datasets used and/or analyzed during the current study are available from the corresponding author upon reasonable request.

\section{Authors' contributions}

XC, FL and ZZT conceived and designed the present study. XC performed the experiments and analyzed the data. XC drafted the initial manuscript. FL and ZZT revised the manuscript. $\mathrm{XC}$ and FL confirmed the authenticity of all the raw data. All authors have read and approved the final manuscript.

\section{Ethics approval and consent to participate}

The present study was approved by the Clinical Research Ethics Committee of Renmin Hospital of Wuhan University [Wuhan, China; approval no. 2020(358)] and written informed consent was provided by all patients prior to the study start. All animal experiments were approved by the Ethics Committee of Animal Experiments of Renmin Hospital of Wuhan University [Wuhan, China; approval no. 2020(421)], and performed in compliance with the laboratory animal management and guidelines.

\section{Patient consent for publication}

Not applicable.

\section{Competing interests}

The authors declare that they have no competing interests.

\section{References}

1. Bray F, Ferlay J, Soerjomataram I, Siegel RL, Torre LA and Jemal A: Global cancer statistics 2018: GLOBOCAN estimates of incidence and mortality worldwide for 36 cancers in 185 countries. CA Cancer J Clin 68: 394-424, 2018.

2. Adham M, Kurniawan AN, Muhtadi AI, Roezin A, Hermani B, Gondhowiardjo S, Tan IB and Middeldorp JM: Nasopharyngeal carcinoma in Indonesia: Epidemiology, incidence, signs, and symptoms at presentation. Chin J Cancer 31: 185-196, 2012.

3. Sun XS, Li XY, Chen QY, Tang LQ and Mai HQ: Future of radiotherapy in nasopharyngeal carcinoma. Br J Radiol 92: 20190209, 2019.

4. Kimura Y, Suzuki D, Tokunaga T, Takabayashi T, Yamada T, Wakisaka N, Yoshizaki T, Murata H, Miwa K, Shoujaku H, et al: Epidemiological analysis of nasopharyngeal carcinoma in the central region of Japan during the period from 1996 to 2005. Auris Nasus Larynx 38: 244-249, 2011. 
5. Qiu S,Lin S,Tham IWK,Pan J,Lu J and Lu JJ: Intensity-modulated radiation therapy in the salvage of locally recurrent nasopharyngeal carcinoma. Int J Radiat Oncol Biol Phys 83: 676-683, 2012.

6. Co J, Mejia MB and Dizon JM: Evidence on effectiveness of intensity-modulated radiotherapy versus 2-dimensional radiotherapy in the treatment of nasopharyngeal carcinoma: Meta-analysis and a systematic review of the literature. Head Neck 38 (Suppl 1): E2130-E2142, 2016.

7. $\mathrm{Xu} \mathrm{ZJ}$, Zheng RS, Zhang SW, Zou XN and Chen WQ: Nasopharyngeal carcinoma incidence and mortality in China in 2009. Chin J Cancer 32: 453-460, 2013.

8. Colaco RJ, Betts G, Donne A, Swindell R, Yap BK, Sykes AJ, Slevin NJ, Homer JJ and Lee LW: Nasopharyngeal carcinoma: A retrospective review of demographics, treatment and patient outcome in a single Centre. Clin Oncol (R Coll Radiol) 25: 171-177, 2013.

9. Jones FS and Jones PL: The tenascin family of ECM glycoproteins: Structure, function, and regulation during embryonic development and tissue remodeling. Dev Dyn An 218: 235-259, 2000.

10. Midwood KS, Chiquet M, Tucker RP and Orend G: Tenascin-C at a glance. J Cell Sci 129: 4321-4327, 2016.

11. Van Obberghen-Schilling E, Tucker RP, Saupe F, Gasser I, Cseh B and Orend G: Fibronectin and Tenascin-C: Accomplices in vascular morphogenesis during development and tumor growth. Int J Dev Biol 55: 511-525, 2011.

12. Midwood KS, Hussenet T, Langlois B and Orend G: Advances in Tenascin-C biology. Cell Mol Life Sci 68: 3175-3199, 2011.

13. Yoshida T, Akatsuka T and Imanaka-Yoshida K: Tenascin-C and integrins in cancer. Cell Adh Migr 9: 96-104, 2015.

14. Lange K, Kammerer M, Saupe F, Hegi ME, Grotegut S, Fluri E and Orend G: Combined lysophosphatidic acid/platelet-derived growth factor signaling triggers glioma cell migration in a Tenascin-C microenvironment. Cancer Res 68: 6942-6952, 2008.

15. Huang W, Chiquet-Ehrismann R, Moyano JV, Garcia-Pardo A and Orend G: Interference of Tenascin-C with syndecan-4 binding to fibronectin blocks cell adhesion and stimulates tumor cell proliferation. Cancer Res 61: 8586-8594, 2001.

16. Oskarsson T, Acharyya S, Zhang XH, Vanharanta S, Tavazoie SF, Morris PG, Downey RJ, Manova-Todorova K, Brogi E and Massagué J: Breast cancer cells produce Tenascin $\mathrm{C}$ as a metastatic niche component to colonize the lungs. Nat Med 17: 867-874, 2011.

17. Beiter K, Hiendlmeyer E, Brabletz T, Hlubek F, Haynl A, Knoll C, Kirchner $\mathrm{T}$ and Jung A: Beta-Catenin regulates the expression of Tenascin-C in human colorectal tumors. Oncogene 24 8200-8204, 2005.

18. Lowy CM and Oskarsson T: Tenascin $\mathrm{C}$ in metastasis: A view from the invasive front. Cell Adh Migr 9: 112-124, 2015.

19. Yoneura N, Takano S, Yoshitomi H, Nakata Y, Shimazaki R, Kagawa S, Furukawa K, Takayashiki T, Kuboki S, Miyazaki M and Ohtsuka M: Expression of annexin II and stromal tenascin $\mathrm{C}$ promotes epithelial to mesenchymal transition and correlates with distant metastasis in pancreatic cancer. Int J Mol Med 42 821-830, 2018

20. Nagaharu K, Zhang X, Yoshida T, Katoh D, Hanamura N, Kozuka Y, Ogawa T, Shiraishi T and Imanaka-Yoshida K Tenascin $\mathrm{C}$ induces epithelial-mesenchymal transition-like change accompanied by SRC activation and focal adhesion kinase phosphorylation in human breast cancer cells. Am J Pathol 178: 754-763, 2011

21. Langfelder P and Horvath S: WGCNA: An R package for weighted correlation network analysis. BMC Bioinformatics 9: 559, 2008.

22. Wan Q, Tang J, Han Y and Wang D: Co-expression modules construction by WGCNA and identify potential prognostic markers of uveal melanoma. Exp Eye Res 166: 13-20, 2018.

23. Bao YN, Cao X, Luo DH, Sun R, Peng LX, Wang L, Yan YP, Zheng LS, Xie P, Cao Y, et al: Urokinase-type plasminogen activator receptor signaling is critical in nasopharyngeal carcinoma cell growth and metastasis. Cell Cycle 13: 1958-1969, 2014.

24. Bose S, Yap LF, Fung M, Starzcynski J, Saleh A, Morgan S Dawson C, Chukwuma MB, Maina E, Buettner M, et al: The ATM tumour suppressor gene is down-regulated in EBV-associated nasopharyngeal carcinoma. J Pathol 217: 345-352, 2009.

25. Tang XR, Li YQ, Liang SB, Jiang W, Liu F, Ge WX, Tang LL, Mao YP, He QM, Yang XJ, et al: Development and validation of a gene expression-based signature to predict distant metastasis in locoregionally advanced nasopharyngeal carcinoma: A retrospective, multicentre, cohort study. Lancet Oncol 19: 382-393, 2018.

26. Torlakovic EE, Nielsen S, Vyberg M and Taylor CR: Getting controls under control: The time is now for immunohistochemistry. J Clin Pathol 68: 879-882, 2015.
27. Liberzon A, Birger C, Thorvaldsdóttir H, Ghandi M, Mesirov JP and Tamayo P: The molecular signatures database (MSigDB) hallmark gene set collection. Cell Syst 1: 417-425, 2015.

28. Livak KJ and Schmittgen TD: Analysis of relative gene expression data using real-time quantitative PCR and the 2(-Delta Delta C(T)) method. Methods 25: 402-408, 2001.

29. Huang SH and O'Sullivan B: Overview of the 8th edition TNM classification for head and neck cancer. Curr Treat Options Oncol 18: 40, 2017.

30. Beckerman P, Qiu C, Park J, Ledo N, Ko YA, Park AD, Han SY, Choi P, Palmer M and Susztak K: Human kidney tubule-specific gene expression based dissection of chronic kidney disease traits. EBioMedicine 24: 267-276, 2017.

31. Tang J, Kong D, Cui Q, Wang K, Zhang D, Gong Y and Wu G: Prognostic genes of breast cancer identified by gene Co-expression network analysis. Front Oncol 8: 374, 2018

32. Rosen EY, Wexler EM, Versano R, Coppola G, Gao F, Winden KD, Oldham MC, Martens LH, Zhou P, Farese RV Jr and Geschwind DH: Functional genomic analyses identify pathways dysregulated by progranulin deficiency, implicating Wnt signaling. Neuron 71: 1030-1042, 2011.

33. Akabani G, Reardon DA, Coleman RE, Wong TZ, Metzler SD, Bowsher JE, Barboriak DP, Provenzale JM, Greer KL, DeLong D, et al: Dosimetry and radiographic analysis of 131I-labeled anti-tenascin 81C6 murine monoclonal antibody in newly diagnosed patients with malignant gliomas: A phase II study. J Nucl Med 46: 1042-1051, 2005.

34. Reardon DA, Akabani G, Coleman RE, Friedman AH, Friedman HS, Herndon JE II, Cokgor I, McLendon RE, Pegram CN, Provenzale JM, et al: Phase II trial of murine (131) I-labeled antitenascin monoclonal antibody 81C6 administered into surgically created resection cavities of patients with newly diagnosed malignant gliomas. J Clin Oncol 20: 1389-1397, 2002.

35. Cokgor I, Akabani G, Kuan CT, Friedman HS, Friedman AH, Coleman RE, McLendon RE, Bigner SH, Zhao XG, Garcia-Turner AM, et al: Phase I trial results of iodine-131-labeled antitenascin monoclonal antibody 81C6 treatment of patients with newly diagnosed malignant gliomas. J Clin Oncol 18: 3862-3872, 2000

36. Sarli B, Topsakal R, Kaya EG, Akpek M, Lam YY and Kaya MG: Tenascin-C as predictor of left ventricular remodeling and mortality in patients with dilated cardiomyopathy. J Investig Med 61: 728-732, 2013

37. Aoki M and Fujishita T: Oncogenic roles of the PI3K/AKT/mTOR axis. In: Current Topics in Microbiology and Immunology. Vol. 407 Springer Verlag, pp153-189, 2017.

38. Jhanwar-Uniyal M, Amin AG, Cooper JB, Das K, Schmidt MH and Murali R: Discrete signaling mechanisms of mTORC1 and mTORC2: Connected yet apart in cellular and molecular aspects. Adv Biol Regul 64: 39-48, 2017.

39. Kim LC, Cook RS and Chen J: MTORC1 and mTORC 2 in cancer and the tumor microenvironment. Oncogene 36: 2191-2201, 2017.

40. Wang F, Meng M, Mo B, Yang Y, Ji Y, Huang P, Lai W, Pan X, You T, Luo H, et al: Crosstalks between mTORC1 and mTORC2 variagate cytokine signaling to control NK maturation and effector function. Nat Commun 9: 4874, 2018.

41. Lee YJ and Han HJ: Troglitazone ameliorates high glucose-induced EMT and dysfunction of SGLTs through PI3K/Akt, GSK-3 $\beta$, Snail1, and $\beta$-catenin in renal proximal tubule cells. Am J Physiol Renal Physiol 298: F1263-F1275, 2010.

42. Byers LA, Diao L, Wang J, Saintigny P, Girard L, Peyton M, Shen L, Fan Y, Giri U, Tumula PK, et al: An epithelial-mesenchymal transition gene signature predicts resistance to EGFR and PI3K inhibitors and identifies Axl as a therapeutic target for overcoming EGFR inhibitor resistance. Clin Cancer Res 19: 279-290, 2013

43. Zhao YR, Wang JL, Xu C, Li YM, Sun B and Yang LY: HEG1 indicates poor prognosis and promotes hepatocellular carcinoma invasion, metastasis, and EMT by activating Wnt/ $\beta$-catenin signaling. Clin Sci 133: 1645-1662, 2019.

44. Xu W, Wang Z, Zhang W, Qian K, Li H, Kong D, Li Y and Tang Y: Mutated K-ras activates CDK8 to stimulate the epithelial-to-mesenchymal transition in pancreatic cancer in part via the Wnt/ $\beta$-catenin signaling pathway. Cancer Lett 356: 613-627, 2015.

This work is licensed under a Creative Commons Attribution-NonCommercial-NoDerivatives 4.0 International (CC BY-NC-ND 4.0) License. 